\title{
Detection of Giardia lamblia by Microscopic Examination, Rapid Chromatographic Immunoassay Test, and Molecular Technique
}

\author{
Amjad Alharbi ${ }^{1}$, Fawzia H. Toulah ${ }^{2}$, Majed H. Wakid ${ }^{3,4}$, Esam Azhar ${ }^{3,4}$, Suha Farraj ${ }^{4}$, Ahmed A. Mirza ${ }^{3}$ \\ 1. Faculty of Science for Girls, Department of Biology, King Abdulaziz University, Jeddah, SAU 2. College of Science, \\ Department of Biology, University of Jeddah, Jeddah, SAU 3. Faculty of Applied Medical Sciences, Department of \\ Medical Laboratory Sciences, King Abdulaziz University, Jeddah, SAU 4. Special Infectious Agents Unit, King Fahd \\ Medical Research Center, Jeddah, SAU
}

Corresponding author: Majed H. Wakid, mwakid@kau.edu.sa

\section{Abstract \\ Background}

Giardia lamblia is a pathogenic intestinal flagellate transmitted by the ingestion of contaminated water or food with the cyst stage of the parasite. Giardiasis can cause severe acute diarrhea and malabsorption or may persist as a chronic infection. Effective treatment and control measures depend on proper laboratory diagnosis using diagnostic methods with high sensitivity and specificity.

\section{Objective}

To compare the sensitivity and specificity of direct smear, Ritchie sedimentation technique, two brands of rapid chromatographic immunoassay test, and real-time polymerase chain reaction (PCR) for the detection of G. lamblia in clinical human fecal samples.

\section{Materials and methods}

Unpreserved 100 stool specimens were collected in clean plastic containers and labeled with the patient's information and examined through light microscopy, immunochromatographic test (ICTs), and real-time PCR.

\section{Results}

Out of 100 fresh stool samples obtained from workers analyzed, real-time PCR targeting the SSU rRNA gene was able to detect Giardia deoxyribonucleic acid (DNA) in (42) samples followed by ImmunoCard STAT! (31) samples (Meridian Bioscience, Germany), direct smear (23) samples, CerTest (19) samples (Biotec, Zaragoza, Spain), and Ritchie technique (17) samples. Real-time PCR was the most sensitive for the diagnosis of $G$. lamblia in comparison to the other techniques.

Received 08/26/2020

Review began 08/28/2020 Review ended 08/31/2020 Published 09/07/2020

\section{() Copyright 2020}

Alharbi et al. This is an open access article distributed under the terms of the Creative Commons Attribution License CC-BY 4.0., which permits unrestricted use, distribution, and reproduction in any medium, provided the original author and source are credited.

\section{Conclusions}

All the techniques investigated were sensitive for the detection of G. lamblia in stool samples. Further studies are recommended using multiplex real-time PCR assay in order to increase the possibility of the presence or absence of the infection.

Categories: Infectious Disease, Healthcare Technology, Epidemiology/Public Health

Keywords: giardia lamblia, diagnosis, parasites, real-time pcr, neglected diseases, saudi arabia, icts

\section{Introduction}

One of the most important causes of parasitic diseases is a flagellated protozoan called Giardia lamblia. The life cycle is simple and direct, including the motile trophozoite and nonmotile cyst stages while the ingestion of cysts in contaminated water or food (fecal-oral route) is the main mode of transmission [1]. The World Health Organization (WHO) reported that 748 million people drink unsafe water, 2.5 billion are without improved sanitation, more than 200 million cases are reported annually, and since 2004, Giardia has been included in the "neglected diseases initiative" [2-3]. Infection with Giardia in many people is asymptomatic while others suffer from acute watery diarrhea, abdominal cramps, nausea, epigastric pain, malabsorption, flatulence, and weight loss [4]. In some patients and in relation to several factors, the infection may sustain and become chronic [5]. Previous studies in Saudi Arabia reported high prevalence rates of intestinal parasitic diseases with a different rate of G. lamblia (2\%-20\%) among various populations [6-9].

The early accurate diagnosis of giardiasis is important for the successful treatment and prevention of 
diseases. The routine laboratory diagnosis is performed for the detection of trophozoites or cysts by microscopic examination of at least three stool samples collected independently [10-11]. This diagnosis depends upon the times of sampling, patient compliance, application of concentration methods, and the expertise of the technologists. Furthermore, in recent years, other methods, such as rapid immunochromatographic tests (ICTs) and molecular techniques, are used mainly for diagnostic or research proposes. The sensitivity and specificity of all diagnostic methods can be improved by including alternative diagnostic procedures that are more rapid and reliable [12]. Isolates of Giardia are classified into eight genotypes and the studies of these genes have indicated evidence of cryptic infection, suggesting the use of molecular diagnostics [13].

The aim of the present study was to compare the sensitivity and specificity of several diagnostic methods: direct smears, Ritchie sedimentation technique, two brands of ICTs, and real-time PCR for the detection of G. lamblia in clinical human fecal samples.

\section{Materials And Methods Specimen collection}

Stool specimens were collected in clean plastic containers from workers recently arrived in Jeddah, Saudi Arabia, during their screening visit to get a residence permit (officially known as Iqama).

\section{Questionnaire form}

The data of patients were collected by interviews in a standard questionnaire that was designed for this study. It included questions on demographic information (age, nationality, the period of residence in Saudi Arabia, and occupation) and some general information about intestinal parasitic infections.

\section{Laboratory examination}

Laboratory microscopic examination of feces was accomplished by using direct smears, the Ritchie technique, Para-Pak trichrome stain. Two brands of rapid chromatographic immunoassay tests were performed according to the manufacturer's instructions. ImmunoCard STAT! CGE (Meridian, Bioscience, Germany) and CerTest (Biotec, Zaragoza, Spain) are designed to identify G. lamblia, Cryptosporidium parvum, and Entamoeba histolytica. Real-time PCR was used to detect the small subunit ribosomal RNA gene (SSU rRNA) of G. lamblia.

\section{Direct smears}

About $2 \mathrm{mg}$ for each stool sample was mixed with a drop of normal saline (0.9\%) and iodine on a clean glass slide (75 X $26 \mathrm{~mm})$. A cover glass ( 22 X $22 \mathrm{~mm}$ ) was placed carefully and then examined by light microscopy using (10x) and (40x) objective lenses.

\section{Ritchie (formal ether) sedimentation technique}

About $2 \mathrm{gm}$ of each stool sample was emulsified in $10 \mathrm{ml}$ of $10 \%$ formal-saline. It was then filtered through two gauze layers fitted in a funnel and centrifuged for $5 \mathrm{~min}$ at $2000 \mathrm{rpm}$. The supernatant was discarded, and the sediment was re-suspended in $10 \mathrm{ml}$ of formal saline (10\%) and mixed very well. After that, $3 \mathrm{ml}$ of diethyl ether was added, shaken vigorously for $10 \mathrm{sec}$, and then centrifuged for $5 \mathrm{~min}$ at $2000 \mathrm{rpm}$. Four layers were formed: the top layer of ether, the plug of the debris, $10 \%$ formal saline, and the sediment layer at the bottom of the tube. The top three layers were removed, and a drop of iodine was mixed with the sediment and then examined using (10x) and (40x) objective lenses [14].

\section{Para-Pak trichrome stain}

Stool samples were fixed in polyvinyl alcohol (PVA). Stool smears were prepared and stained by Wheatley trichrome stain according to the manufacturer's instructions, (Para-Pak ${ }^{\circledR}$ Trichrome Stain, Meridian, Bioscience, Germany). Smears were air-dried then stained with trichrome stain for 6-8 min, placed in acid ethanol for 5-10 sec, then two quick dips in (95\%) ethanol. The slides were immersed two times in (95\%) ethanol for $5 \mathrm{~min}$, then in (96-100\%) ethanol for $3 \mathrm{~min}$, and finally placed in xylene for $3 \mathrm{~min}$. Finally, each slide was mounted with a coverslip (22 X $40 \mathrm{~mm}$ ) and examined using an oil immersion (100x) objective lens.

\section{ImmunoCard STAT! CGE}

For each specimen, $1 \mathrm{ml}$ of the diluent was transferred into a $15 \mathrm{ml}$ centrifuge tube. Thereafter, approximately $50 \mathrm{mg}$ of each stool specimen was added and mixed gently, then centrifuged for $5 \mathrm{~min}$ at 3000 rpm. Next, $125 \mu \mathrm{l}$ of each prepared specimen was placed into the sample port of the device and the results were interpreted after $10 \mathrm{~min}$. A purple band appears at the control line $(\mathrm{C})$, indicating that the test was completed successfully. The blue band at position 1 on the device frame is indicative of the presence of $C$. parvum antigens. In the presence of G. lamblia antigens, a red/pink color is observed at band 2 . A green band appearing at position 3 is related to E. histolytica antigens. 


\section{CerTest}

One-hundred twenty-five (125) mg was added into the diluent collection tube, mixed very well, and then shaken vigorously for seconds. Four drops of the prepared specimen were dispensed in each of the circular windows. The test was interpreted after $10 \mathrm{~min}$ with a green band-of-control line. The formation of a red band at the test line is indicative of the presence of the investigated parasite.

\section{DNA isolation}

Stool samples were subjected to DNA extraction using the QIAamp DNA Stool Mini Kit (Qiagen, Germany) protocol. Each DNA sample was eluted in a final volume of $100 \mu \mathrm{l}$ and stored at $-80^{\circ} \mathrm{C}$ until needed.

\section{Real-time PCR amplification}

The target gene of the real-time PCR assay is the SSU rRNA gene. DNA was amplified and detected for $G$. lamblia specifically. To select the specific Giardia sequence, alignments were made of 31 GenBank sequences that included 16 Giardia and 15 sequences of other parasites and bacteria (non-pathogenic). The Giardia-specific primers and probe set consisted of the forward primer Giardia F, the reverse primer Giardia $\mathrm{R}$, and the Giardia specific double-labeled probe Giardia T (Humanizing Genomic Macrogen Clinical Lab, Korea) [15]: Giardia F (5 -GACGGCTCAGGACAACGGTT-3 ${ }^{\circ}$; positions 80-99), Giardia R (5 TTGCCAGCGGTGTCCG-3 ; positions 142-127) and Giardia T (FAM-5 -CCCGCGGCGGTCCCTGCTAG-3 TAMRA; positions 105-124).

\section{Stock primers and probe}

According to the manufacturer's instructions, to reach $100 \mathrm{pmol} / \mu \mathrm{l}, 250 \mu \mathrm{l}$ of nuclease-free water was added for each primer and $280 \mu \mathrm{l}$ was added for the probe.

\section{Working primers and probe}

Fifty $\mu \mathrm{l}$ from each stock primer was added to $50 \mu \mathrm{l}$ nuclease-free water to prepare $50 \mathrm{pmol} / \mu \mathrm{l}$. From this, 10 $\mu \mathrm{l}$ was mixed with $90 \mu \mathrm{l}$ of nuclease-free water. Thirty $\mu \mathrm{l}$ from the stock probe was added to $70 \mu \mathrm{l}$ nucleasefree water to prepare $30 \mathrm{pmol} / \mu \mathrm{l}$. From this, $10 \mu \mathrm{l}$ was mixed with $90 \mu \mathrm{l}$ of nuclease-free water. All working primers and probes were stored at $-20^{\circ} \mathrm{C}$ until needed.

\section{Real-time PCR master mix preparation}

The real-time PCR master mix was prepared according to QuantiTect ${ }^{\circledR}$ Probe PCR Kit instructions (Qiagen, Germany) in a $1.5 \mathrm{ml}$ microcentrifuge tube, vortexed very well, and then briefly centrifuged at full speed. After that, the reaction mix was dispensed in a volume of $15.5 \mu$ using a standard PCR plate containing 96 wells strips tubes. Then, $9.5 \mu \mathrm{l}$ of the template DNA was added to the individual wells containing the reaction mix. The plate was then transferred into Applied Biosystems 7500 Fast cycler (Foster City, California), to start the cycling program.

\section{Real-time PCR data analysis}

Data analysis was performed with the Applied Biosystems 7500 Fast System by calculating the threshold cycle number (Ct value) that presented the positive amplification of gene in a real-time cycler number.

\section{Statistical analysis}

Categorical data were reported as frequency and percentage (\%). Data were analyzed using SPSS (version 21, IBM Corp., Armonk, NY). A P-value of $<0.05$ value was accepted as statistically significant (corresponding to 95\% confidence intervals (CI)). Sensitivity, specificity, PPV, NPV, and accuracy were calculated to test the diagnostic yield.

\section{Results}

Out of 100 fecal samples analyzed, 48 were positive for G. lamblia, 18 samples for E. histolytica, nine samples for C. parvum, three samples for E. coli, three samples for hookworms, two samples for Trichuris trichiura, two samples for Enterobius vermicularis, and one sample for each of the following: Endolimax nana, Hymenolepis nana, and Taenia spp.

Table 1 summarizes the demographic characteristics of the study subjects. All subjects were male workers aged from 20 to 53 years $(32.09 \pm 8.598)$, mainly from Pakistan. Most of the stool samples were soft (49\%) and loose (48\%) while three patients produced watery stool. 


\section{Cureus}

\begin{tabular}{|c|c|c|c|c|}
\hline \multirow{2}{*}{ Country of origin } & \multirow{2}{*}{$\begin{array}{l}\text { Frequencies } \\
\mathrm{N}\end{array}$} & \multicolumn{3}{|c|}{ Infected cases } \\
\hline & & $\mathrm{n}$ & $(\%)^{\mathrm{a}}$ & $(\%)^{b}$ \\
\hline Bangladesh & 7 & 3 & 42.86 & 4.84 \\
\hline Egypt & 12 & 6 & 50 & 9.68 \\
\hline India & 31 & 18 & 58.06 & 29.03 \\
\hline Nepal & 2 & 2 & 100 & 3.23 \\
\hline Pakistan & 36 & 27 & 75 & 43.55 \\
\hline Philippines & 4 & 1 & 25 & 1.61 \\
\hline Sri Lanka & 2 & 1 & 50 & 1.61 \\
\hline Sudan & 4 & 3 & 75 & 4.84 \\
\hline Yemen & 2 & 1 & 50 & 1.61 \\
\hline Total & 100 & 62 & -- & 100 \\
\hline
\end{tabular}

\section{TABLE 1: Demographic characteristics}

a: within the same nationality; b: within all infected cases (62)

Out of the 100 samples screened for G. lamblia, real-time PCR was able to detect Giardia DNA in 42 samples followed by ImmunoCard STAT! CGE (31), direct smears (23), CerTest (19), and the Ritchie sedimentation technique (17).

Considering real-time PCR as a nominated golden standard, ImmunoCard STAT! CGE revealed the highest sensitivity followed by direct smears (Table 2). ImmunoCard STAT! CGE was acceptable. The area under the curve is 0.746 , Std. Error $=0.053$, p-value $<0.0005$ with $95 \% \mathrm{CI}(0.643-0.849)$. CerTest was acceptable. The area under the curve is 0.706 , Std. Error $=0.056$, p-value $<0.0005$ with $95 \% \mathrm{CI}(0.596-0.815)$. The Ritchie technique was acceptable. The area under the curve is 0.702 , Std. Error $=0.056$, p-value $=0.001$ with $95 \%$ CI $(0.592-$ 0.812). Direct smears were acceptable. The area under the curve is 0.753 , Std. Error $=0.053$, p-value $<0.0005$ with 95\% CI (0.649-0.857) (Figure 1). 


\section{Cureus}

\begin{tabular}{|c|c|c|c|c|c|c|c|c|c|}
\hline \multirow{2}{*}{ Test } & & \multicolumn{2}{|c|}{ Real-time PCR } & \multirow{2}{*}{ Sensitivity \% } & \multirow{2}{*}{ Specificity \% } & \multirow{2}{*}{ PPV \% } & \multirow{2}{*}{ NPV \% } & \multirow{2}{*}{$95 \% \mathrm{CI}$} & \multirow{2}{*}{ P-value } \\
\hline & & $\mathbf{P}$ & $\mathrm{N}$ & & & & & & \\
\hline \multirow[b]{2}{*}{ Immuno Card STAT! CGE } & $\mathrm{P}$ & $\mathrm{TP}_{25}$ & $\mathrm{FP}_{6}$ & \multirow[b]{2}{*}{ (59.52) } & \multirow[b]{2}{*}{$(89.65)$} & \multirow[b]{2}{*}{ (80.64) } & \multirow[b]{2}{*}{$(75.36)$} & \multirow[b]{2}{*}{$(0.64-0.85)$} & \multirow[b]{2}{*}{$P<0.001$} \\
\hline & $\mathrm{N}$ & $\mathrm{FN}_{17}$ & $\mathrm{TN}_{52}$ & & & & & & \\
\hline \multirow[b]{2}{*}{ CerTest } & $P$ & $\mathrm{TP}_{18}$ & $\mathrm{FP}_{1}$ & \multirow[b]{2}{*}{ (42.86) } & \multirow[b]{2}{*}{$(98.27)$} & \multirow{2}{*}{ (94.74) } & \multirow[b]{2}{*}{$(70.37)$} & \multirow[b]{2}{*}{$(0.60-0.82)$} & \multirow[b]{2}{*}{$P<0.001$} \\
\hline & $\mathrm{N}$ & $\mathrm{FN}_{24}$ & $\mathrm{TN}_{57}$ & & & & & & \\
\hline \multirow[b]{2}{*}{ Ritchie } & $P$ & $\mathrm{TP}_{17}$ & $\mathrm{FP}_{0}$ & \multirow[b]{2}{*}{ (40.47) } & \multirow[b]{2}{*}{ (100) } & \multirow[b]{2}{*}{ (100) } & \multirow[b]{2}{*}{ (69.88) } & \multirow[b]{2}{*}{$(0.60-0.81)$} & \multirow[b]{2}{*}{$P<0.001$} \\
\hline & $\mathrm{N}$ & $\mathrm{FN}_{25}$ & $\mathrm{TN}_{58}$ & & & & & & \\
\hline \multirow{2}{*}{ Direct $\mathbf{s}$} & $\mathbf{P}$ & $\mathrm{TP}_{22}$ & $\mathrm{FP}_{1}$ & \multirow{2}{*}{ (52.38) } & \multirow{2}{*}{ (98.27) } & \multirow{2}{*}{ (95.65) } & \multirow{2}{*}{ (74.02) } & \multirow{2}{*}{$(0.65-0.86)$} & \multirow[b]{2}{*}{$P<0.001$} \\
\hline & $\mathrm{N}$ & $\mathrm{FN}_{20}$ & TN57 & & & & & & \\
\hline
\end{tabular}

\section{TABLE 2: Sensitivity, specificity, and accuracy of diagnostic tools with real-time PCR}

N: Negative, P: Positive, TP: True-positive, FP: False-negative, TN: True-negative, FN: False-negative, PPV: Positive predictive value, NPV: Negative predictive value

ImmunoCard STAT!: Meridian Bioscience, Germany; CerTest: Biotec, Zaragoza, Spain

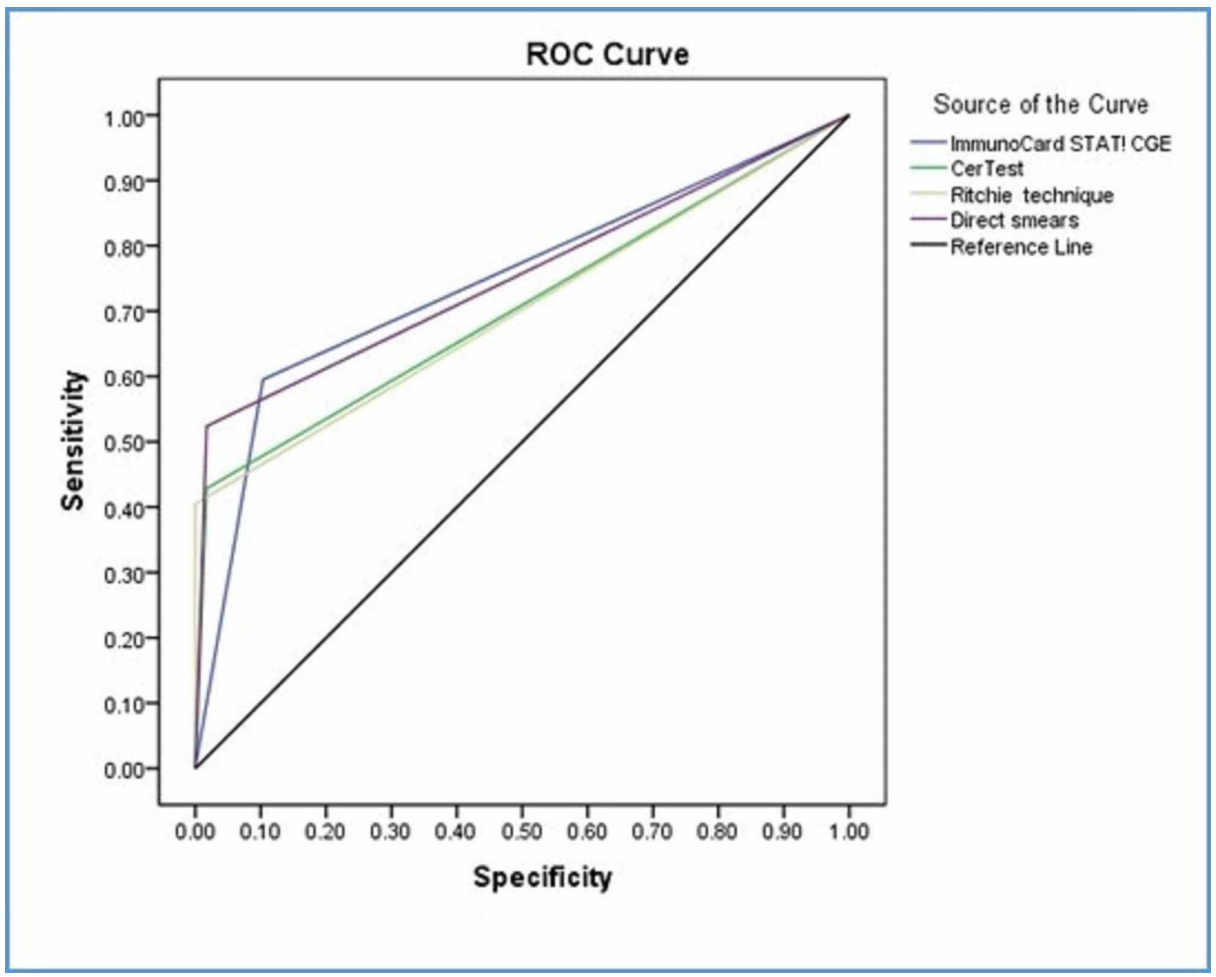

FIGURE 1: Sensitivity, specificity, and accuracy of diagnosis tools with real-time PCR

PCR: polymerase chain reaction

When direct smears assumed as a nominated golden standard, real-time PCR showed the highest sensitivity followed by ImmunoCard STAT! CGE and then the CerTest and Ritchie technique (Table 3). ImmunoCard STAT! CGE was excellent. The area under the curve is 0.892, Std. Error $=0.041$, p-value $<0.0005$ with $95 \%$ CI (0.812-0.972). CerTest was excellent. The area under the curve is 0.857 , Std. Error $=0.056, \mathrm{p}$-value $<0.0005$ 


\section{Cureus}

with 95\% CI (0.746-0.967). The Ritchie technique was excellent. The area under the curve is 0.870 , Std. Error $=0.056, \mathrm{p}$-value $<0.0005$ with $95 \% \mathrm{CI}(0.760-0.979)$. Real-time PCR was excellent. The area under the curve is 0.848 , Std. Error $=0.041$, p-value $<0.0005$ with $95 \%$ CI $(0.768-0.929)$ (Figure 2).

\begin{tabular}{|c|c|c|c|c|c|c|c|c|c|}
\hline \multirow{2}{*}{ Test } & & \multicolumn{2}{|c|}{ Direct smears } & \multirow{2}{*}{ Sensitivity \% } & \multirow{2}{*}{ Specificity \% } & \multirow{2}{*}{ PPV \% } & \multirow{2}{*}{ NPV \% } & \multirow{2}{*}{$95 \% \mathrm{Cl}$} & \multirow{2}{*}{$P$ value } \\
\hline & & $P$ & $\mathbf{N}$ & & & & & & \\
\hline \multirow{2}{*}{ Immuno Card STAT! CGE } & $P$ & $\mathrm{TP}_{21}$ & $\mathrm{FP}_{10}$ & \multirow[b]{2}{*}{$(91.3)$} & \multirow[b]{2}{*}{ (87.01) } & \multirow[b]{2}{*}{$(67.74)$} & \multirow[b]{2}{*}{ (97.10) } & \multirow[b]{2}{*}{$(0.81-0.98)$} & \multirow[b]{2}{*}{$P<0.001$} \\
\hline & $\mathrm{N}$ & $\mathrm{FN}_{2}$ & $\mathrm{TN}_{67}$ & & & & & & \\
\hline \multirow[b]{2}{*}{ CerTest } & $P$ & $\mathrm{TP}_{17}$ & $\mathrm{FP}_{2}$ & \multirow{2}{*}{ (73.91) } & \multirow{2}{*}{$(97.40)$} & \multirow{2}{*}{$(89.47)$} & \multirow[b]{2}{*}{ (92.59) } & \multirow[b]{2}{*}{$(0.75-0.97)$} & \multirow{2}{*}{$P<0.001$} \\
\hline & $\mathrm{N}$ & $\mathrm{FN}_{6}$ & $\mathrm{TN}_{75}$ & & & & & & \\
\hline \multirow{2}{*}{ Ritchie } & $P$ & $\mathrm{TP}_{17}$ & $\mathrm{FP}_{0}$ & \multirow{2}{*}{ (73.91) } & \multirow{2}{*}{ (100) } & \multirow{2}{*}{ (100) } & \multirow{2}{*}{$(92.77)$} & \multirow{2}{*}{$(0.76-0.98)$} & \multirow{2}{*}{$P<0.001$} \\
\hline & $\mathrm{N}$ & $\mathrm{FN}_{6}$ & $\mathrm{TN}_{77}$ & & & & & & \\
\hline \multirow{2}{*}{ Real-time PCR } & $\mathbf{P}$ & $\mathrm{TP}_{22}$ & $\mathrm{FP}_{20}$ & \multirow{2}{*}{ (95.65) } & \multirow{2}{*}{$(74.03)$} & \multirow{2}{*}{ (52.38) } & \multirow{2}{*}{ (98.28) } & \multirow{2}{*}{$(0.77-0.93)$} & \multirow{2}{*}{$P<0.001$} \\
\hline & & & & & & & & & \\
\hline
\end{tabular}

\section{TABLE 3: Sensitivity, specificity, and accuracy of diagnostic tools with direct smears}

N: Negative, P: Positive, TP: True-positive, FP: False-negative, TN: True-negative, FN: False-negative, PPV: Positive predictive value, NPV: Negative predictive value

ImmunoCard STAT!: Meridian Bioscience, Germany; CerTest: Biotec, Zaragoza, Spain

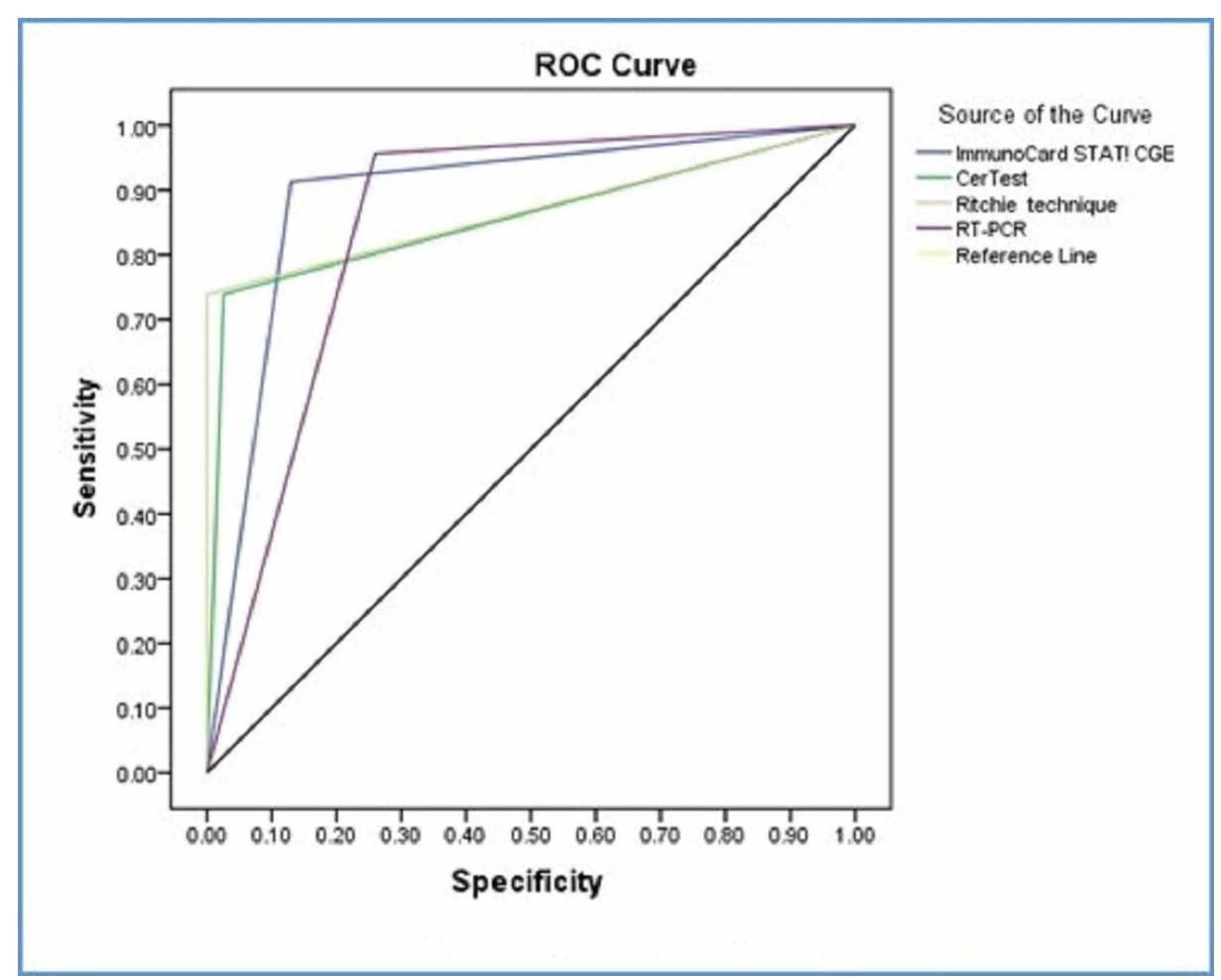

FIGURE 2: Sensitivity, specificity, and accuracy of diagnosis tools with direct smears

When the Ritchie technique considered as a nominated golden standard, all tests had (100\%) sensitivity with 


\section{Cureus}

the Ritchie technique (Table 4). ImmunoCard STAT! CGE was outstanding. The area under the curve is 0.916, Std. Error $=0.027$, p-value $<0.0005$ with $95 \%$ CI $(0.862-0.969)$. CerTest was outstanding. The area under the curve is 0.988 , Std. Error $=0.010$, p-value $<0.0005$ with $95 \%$ CI $(0.969-1)$. Real-time PCR was excellent. The area under the curve is 0.849 , Std. Error $=0.038$, p-value $<0.0005$ with $95 \% \mathrm{CI}(0.776-0.923)$. Direct smears were outstanding. The area under the curve is 0.964 , Std. Error $=0.018$, p-value $<0.0005$ with $95 \% \mathrm{CI}(0.929-$ 0.998) (Figure 3).

\begin{tabular}{|c|c|c|c|c|c|c|c|c|c|}
\hline \multirow{2}{*}{ Test } & & \multicolumn{2}{|c|}{ Ritchie } & \multirow{2}{*}{ Sensitivity \% } & \multirow{2}{*}{ Specificity \% } & \multirow{2}{*}{ PPV \% } & \multirow{2}{*}{ NPV \% } & \multirow{2}{*}{$95 \% \mathrm{Cl}$} & \multirow{2}{*}{ P-value } \\
\hline & & $\mathbf{P}$ & $\mathrm{N}$ & & & & & & \\
\hline \multirow{2}{*}{ Immuno Card STAT! CGE } & $\mathbf{P}$ & $\mathrm{TP}_{17}$ & $\mathrm{FP}_{14}$ & \multirow{2}{*}{$(100)$} & \multirow{2}{*}{ (83.13) } & \multirow{2}{*}{ (54.84) } & \multirow{2}{*}{ (100) } & \multirow{2}{*}{$(0.86-0.97)$} & \multirow{2}{*}{$P<0.001$} \\
\hline & $\mathrm{N}$ & $\mathrm{FN}_{0}$ & $\mathrm{TN}_{69}$ & & & & & & \\
\hline \multirow[b]{2}{*}{ CerTest } & $P$ & $\mathrm{TP}_{17}$ & $\mathrm{FP}_{2}$ & \multirow[b]{2}{*}{$(100)$} & \multirow[b]{2}{*}{ (97.59) } & \multirow[b]{2}{*}{ (89.47) } & \multirow[b]{2}{*}{ (100) } & \multirow[b]{2}{*}{$(0.97-1.00)$} & \multirow[b]{2}{*}{$P<0.001$} \\
\hline & $\mathrm{N}$ & $\mathrm{FN}_{0}$ & $\mathrm{TN}_{81}$ & & & & & & \\
\hline \multirow{2}{*}{ Real-time PCR } & $P$ & $\mathrm{TP}_{17}$ & $\mathrm{FP}_{25}$ & \multirow{2}{*}{$(100)$} & \multirow{2}{*}{ (69.88) } & \multirow{2}{*}{ (40.48) } & \multirow{2}{*}{ (100) } & \multirow{2}{*}{$(0.78-0.92)$} & \multirow{2}{*}{$P<0.001$} \\
\hline & $\mathrm{N}$ & $\mathrm{FN}_{0}$ & $\mathrm{TN}_{58}$ & & & & & & \\
\hline \multirow{2}{*}{ Direct smears } & $P$ & $\mathrm{TP}_{17}$ & $\mathrm{FP}_{6}$ & \multirow{2}{*}{ (100) } & \multirow{2}{*}{ (92.77) } & \multirow{2}{*}{ (73.91) } & \multirow{2}{*}{ (100) } & \multirow{2}{*}{ (0.93-1.00) } & \multirow{2}{*}{$P<0.00$} \\
\hline & $N$ & $\mathrm{FN}_{0}$ & $\mathrm{TN}_{77}$ & & & & & & \\
\hline
\end{tabular}

TABLE 4: Sensitivity, specificity, and accuracy of diagnostic tools with the Ritchie technique

N: Negative, P: Positive, TP: True-positive, FP: False-negative, TN: True-negative, FN: False-negative, PPV: Positive predictive value, NPV: Negative predictive value

ImmunoCard STAT!: Meridian Bioscience, Germany; CerTest: Biotec, Zaragoza, Spain

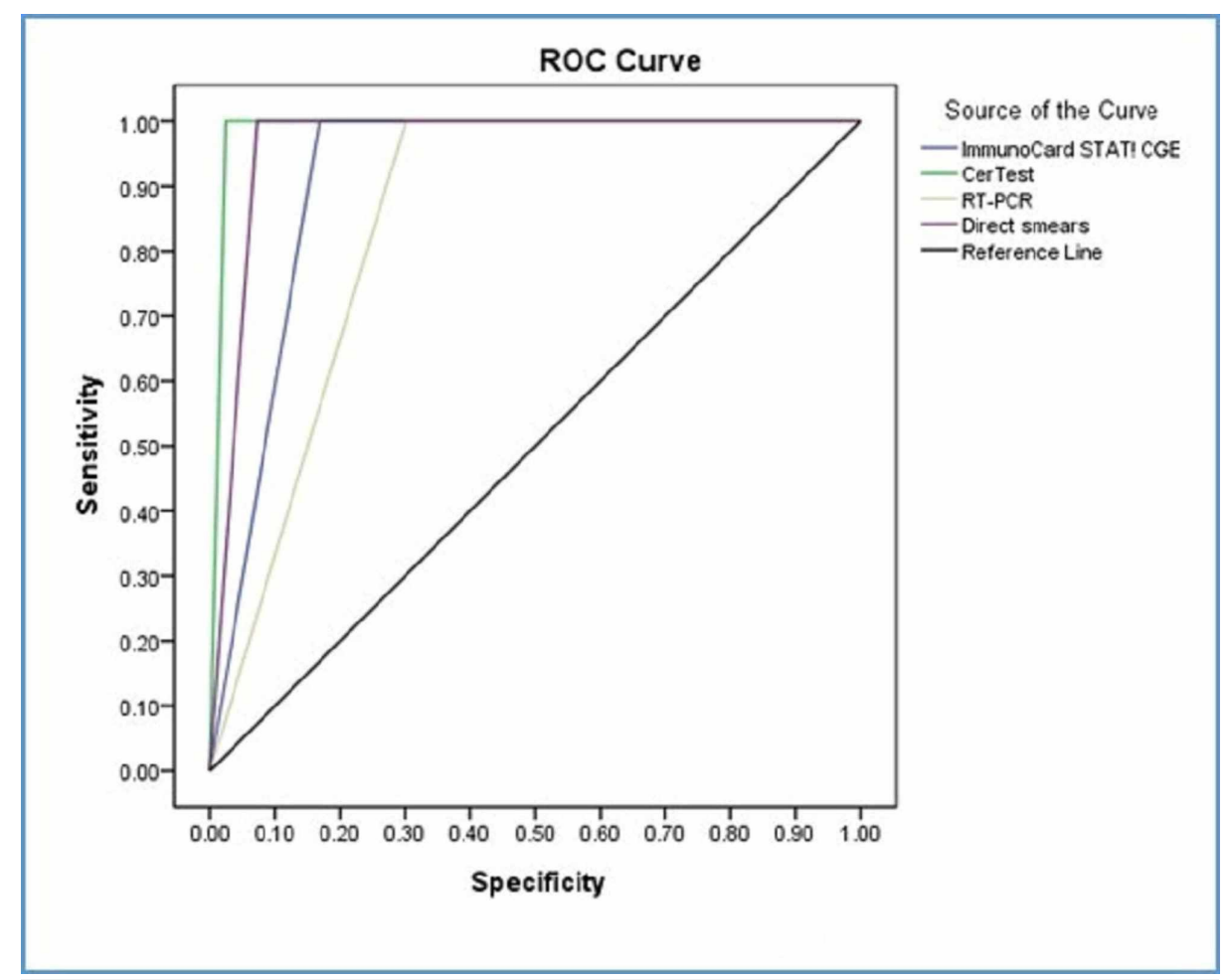

FIGURE 3: Sensitivity, specificity, and accuracy of diagnostic tools with the Ritchie technique 


\section{Discussion}

Intestinal parasitic infections are among the major public health problems in tropical and sub-tropical parts of the world, particularly in rural communities with poor sanitation and poor personal hygiene behaviors. The goal of our study was to compare the sensitivity and specificity of three diagnostic methods: light microscopy, ICTs, and real-time PCR for the detection of G. lamblia in clinical human fecal samples.

Light microscopy is still considered the reference standard access to the fecal parasitological laboratories but there is growing interest in alternative detection methods to overcome the current limitations of microscopic examination. We accomplished a microscopic examination by using direct smears, and the Ritchie technique. The Para-Pak trichrome stain was used to confirm the morphological features for trophozoites and cysts for protozoa parasites. Meanwhile, DNA detection by PCR is offering a better turnaround time and ICTs are commercially available and widely used in clinical laboratories, with limited capacities for diagnostic complexity [16].

Stool samples were collected from non-Saudi workers applying for a residence permit (Iqama). Non-Saudis represent around $30 \%$ of the population in Saudi Arabia [17]. All subjects submitted non-formed stool specimens ranging from soft to watery. Similar results were revealed by a study about the detection of gastrointestinal pathogens in migrant workers in Qatar [18].

Out of the 100 fecal samples analyzed for G. lamblia detection, 42 were found positive by real-time PCR, 31 by ImmunoCard STAT! CGE, 23 by direct smears, 19 by CerTest, and 17 by the Ritchie technique. In 2016, Ahmed and others [19] studied the prevalence of three recognized enteric protozoa; E. histolytica, G. lamblia, and Cryptosporidium spp. among children in Bangladesh. Regarding the variation in their study subject, the prevalence of giardiasis was (50.6\%), (26.7\%), and (3.3\%) by using real-time PCR, ICTs, and direct microscopy respectively. The authors also observed that the positive samples by real-time PCR but negative by the other techniques showed higher $\mathrm{Ct}$ values due to the small number of parasites in those samples that fell below the other methods limit of detection. Our finding is in agreement with that observation. The variation in our results between microscopic examination using direct smears and the Ritchie technique is due to the ability of each technique for the detection of cyst and trophozoite. Direct smears detect both cyst and trophozoite stages while the Ritchie technique is applicable to the cyst stage only [10]. Using direct smears, we observed two cases with only trophozoites and one case with both trophozoites and cysts while none of the trophozoites was detected with the Ritchie technique.

A study conducted in Mozambique for the detection of intestinal parasites in fecal samples showed that the sensitivity of real-time PCR for the detection of each of the parasite species was higher than direct smears, Ritchie technique, Kato smear, Baermann, and coproculture [20]. The workers noticed that real-time PCRpositive samples, but negative during microscopy had higher $\mathrm{Ct}$ values (significantly lower DNA loads) than samples that were positive by both techniques. On the other hand, some samples were positive only by microscopy but negative by real-time PCR. Moreover, a recent study reported the detection of a low number of parasites by light microscopy but negative by PCR [21]. In our study, one sample was positive by routine microscopy and undetectable by real-time PCR; this was fairly in agreement with the above-mentioned studies. The microscopic examination and the DNA isolation usually use a small portion of feces so it might be in some instances that the parasite is observed by light microscopy but missed by PCR. This variation between techniques might be due to the dispersion of cysts within the subsampling due to the nonhomogeneous structure in some stool samples besides the reported non-uniform structure of the intestinal parasites' excretion in the stool [22].

Nominating real-time PCR as a gold standard, ImmunoCard STAT! CGE showed a higher sensitivity (59.5\%) than both direct smears and the Ritchie technique (52.4\% and 40.5\%), respectively (Table 2). A study in Egypt revealed higher sensitivity for ICTs than microscopy when comparing the PCR technique detecting the 18S and tpi genes of giardiasis [23]. Rapid immunoassays kits provide sufficient sensitivities and specificities in direct detection, particularly when using a single stool sample [24].

Seven negative samples in real-time PCR were positive by other tests, therefore, they were suspected to be false-positive; six with ImmunoCard STAT! CGE and one with CerTest. The one giardiasis positive sample with CerTest could be due to cross-reactivity, as the specimen comprised other intestinal parasites, including E. histolytica. Interestingly, this sample was negative by direct smears as well. However, the suspected six false-positive samples in ImmunoCard STAT! CGE could be due to a cryptic giardiasis infection or the persistence of antigen shading after treatment rather than true cross-reactivity [25]. G. lamblia DNA can be found in feces after the parasite clearance and may occasionally produce false-positive PCR results. Moreover, real-time PCR and ICTs may generate false-negative results because of the intermittent patterns of cysts shedding and the number of stool samples required for analysis [26].

Using direct smears as the reference method, real-time PCR showed the highest sensitivity, followed by ImmunoCard STAT! CGE, then CerTest, and finally the Ritchie technique (95.7\%, 91.3\%, 73.9\%, and 73.9\%), respectively (Table 3). This finding contrasts with a study in Germany, as the two ICTs showed a sensitivity 
of $72.9 \%$ and $93.8 \%$, respectively, while PCR showed a sensitivity of $85.4 \%$ [27]. This could be explained by the high concentration of DNase in the samples that inhibit the PCR diagnostics from this material.

Using the Ritchie technique as the reference method, the sensitivity for all the diagnostic tests has reached $100 \%$ while the specificities ranged from $69.9 \%$ to $97.6 \%$ (Table 4 ). Another study reported the low sensitivity of ImmunoCard STAT! CGE (65.3\%) by using formol concentration as the golden standard for the detection of Giardia in fecal samples in Central Africa [28]. The low sensitivity of ICTs could be related to the non-specificity of the antibody-based method owing to cross-reactivity with other microorganisms. Meanwhile, a higher sensitivity of the ImmunoCard STAT! CGE (93.5\%) was observed in a previous study [29]. A similar observation was reported after using saturated sodium nitrate flotation as the golden standard for the detection of G. lamblia [30], and the sensitivities of the PCR and the immunofluorescence assay were $97.3 \%$ and $91.9 \%$, respectively, while the specificity of both was $100 \%$.

\section{Conclusions}

In conclusion, with some variations, all the investigated techniques were applicable for the detection of $G$. lamblia in stool samples. The real-time PCR assay was revealed as the most accurate diagnosis of giardiasis. ICTs proved to be practical, easy to perform, time-saving, and beneficial to analyze a low number of samples. It can be a valuable diagnostic tool in case microscopic expertise is limited. Wet mount microscopy and the Ritchie technique are still important methods for the detection of gastrointestinal parasites when a skilled technologist tests the samples.

\section{Additional Information \\ Disclosures}

Human subjects: Consent was obtained by all participants in this study. Saudi Ministry of Health, Directorate of Health Affairs in Jeddah issued approval A00366. Consent was obtained by all participants in this study. The Ethics and Research Committee of the Directorate of Health Affairs, Ministry of Health, Jeddah, Saudi Arabia, issued approval A00366. Animal subjects: All authors have confirmed that this study did not involve animal subjects or tissue. Conflicts of interest: In compliance with the ICMJE uniform disclosure form, all authors declare the following: Payment/services info: All authors have declared that no financial support was received from any organization for the submitted work. Financial relationships: All authors have declared that they have no financial relationships at present or within the previous three years with any organizations that might have an interest in the submitted work. Other relationships: All authors have declared that there are no other relationships or activities that could appear to have influenced the submitted work.

\section{Acknowledgements}

The authors would like to thank the Ministry of Health, Directorate of Health Affairs in Jeddah, for granting ethical approval and help in the collections of samples. This work was supported by funds from King Abdulaziz City for Science and Technology (37-1198). Thanks are also extended to the Faculty of Science/Department of Biology, the Faculty of Applied Medical Sciences/Department of Medical Laboratory Sciences, and finally to the Special Infectious Agents Unit, King Fahd Medical Research Center, KAU, for providing all the necessary facilities and support.

\section{References}

1. Lipoldová M: Giardia and Vilém Dušan Lambl. PLoS Negl Trop Dis. 2014, 8:e2686. 10.1371/journal.pntd.0002686

2. Soares R, Tasca T: Giardiasis: an update review on sensitivity and specificity of methods for laboratorial diagnosis. J Microbiol Methods. 2016, 129:98-102. 10.1016/j.mimet.2016.08.017

3. Savioli L, Smith H, Thompson A: Giardia and Cryptosporidium join the 'neglected diseases initiative' . Trends Parasitol. 2006, 22:203-208. 10.1016/j.pt.2006.02.015

4. Bartelt LA, Sartor RB: Advances in understanding Giardia: determinants and mechanisms of chronic sequelae. F1000Prime Rep. 2015, 7:62. 10.12703/P7-62

5. Escobedo AA, Hanevik K, Almirall P, Cimerman S, Alfonso M: Management of chronic Giardia infection. Expert Rev Anti Infect Ther. 2014, 12:1143-1157. 10.1586/14787210.2014.942283

6. Abahussain N: Prevalence of intestinal parasites among expatriate workers in Al-Khobar, Saudi Arabia . Middle East J Fam Med. 2005, 3:17-21.

7. Wakid MH: Distribution of intestinal parasites among food handlers in Jeddah, Saudi Arabia . J Parasit Dis. 2006, 30:146-152.

8. Wakid MH, Azhar E, Zafar TA: Intestinal Parasitic infection among food handlers in the Holy City of Makkah during Hajj season: 1428 Hegira (2007G). J King Saud Univ Sci. 2009, 16:39-52. 10.4197/med.16-1.4

9. Imam NF, Abdulbaqi ZB, Fahad RA: The prevalence of intestinal parasitic infections among foreign workers in Madinah, Kingdom of Saudi Arabia. Saudi J Med Med Sci. 2015, 3:112-117. 10.4103/1658-631X.156414

10. Shalaby NM, Wakid MH: Giardiasis in man: review and updates. JKAU Med Sci. 2014, 21:81-94. 10.4197/Med.21-1.6

11. Uehlinger FD, Naqvi SA, Greenwood SJ, McClure JT, Conboy G, O’Handley R, Barkemae HW: Comparison of five diagnostic tests for Giardia duodenalis in fecal samples from young dogs. Vet Parasitol. 2017, 244:91-96. 10.1016/j.vetpar.2017.07.030 
12. Kosack CS, Page AL, Klatser PR: A guide to aid the selection of diagnostic tests . Bull World Health Organ. 2017, 95:639-645. 10.2471/BLT.16.187468

13. Mejia R, Vicuña Y, Broncano N, et al.: A novel, multi-parallel, real-time polymerase chain reaction approach for eight gastrointestinal parasites provides improved diagnostic capabilities to resource-limited at-risk populations. Am J Trop Med Hyg. 2013, 88:1041-1047. 10.4269/ajtmh.12-0726

14. Wakid MH: Improvement of Ritchie technique by identifying the food that can be consumed pre-analysis . J Appl Sc Res. 2009, 5:293-296.

15. Verweij JJ, Schinkel J, Laeijendecker D, van Rooyen M A, van Lieshout L, Polderman AM: Real-time PCR for the detection of Giardia lamblia. Mol Cell Probes. 2003, 17:223-225. 10.1016/s0890-8508(03)00057-4

16. Mchardy IH, Wu M, Shimizu-Cohen R, Couturier MR, Humphries RM: Detection of intestinal protozoa in the clinical laboratory. J Clin Microbiol. 2014, 52:712-720. 10.1128/JCM.02877-13

17. Saudi Arabia's population statistics of 2019. (2019). Accessed: August 26, 2019: https://www.globalmediainsight.com/blog/saudi-arabia-population-statistics/.

18. Humphrey JM, Ranbhise S, Ibrahim E, Al-Romaihi HE, Farag E, Abu-Raddad LJ, Glesby MJ: Multiplex polymerase chain reaction for detection of gastrointestinal pathogens in migrant workers in Qatar. Am J Trop Med Hyg. 2016, 95:1330-1337. 10.4269/ajtmh.16-0464

19. Ahmed T, Khanum H, Uddin MS, Barua P, Arju T, Kabir M, Haque R: Entamoeba histolytica, Giardia lamblia and Cryptosporidium spp. infection in children in an urban slum area of Bangladesh. Biores Commun. 2016, 2:175-181.

20. Meurs L, Polderman AM, Melchers NVV, et al.: Diagnosing polyparasitism in a high-prevalence setting in Beira, Mozambique: detection of intestinal parasites in fecal samples by microscopy and real-time PCR. PLoS Negl Trop Dis. 2017, 11:0005310. 10.1371/journal.pntd.0005310

21. Llewellyn S, Inpankaew T, Nery SV, et al.: Application of a multiplex quantitative PCR to assess prevalence and intensity of intestinal parasite infections in a controlled clinical trial. PLoS Negl Trop Dis. 2016, 10:0004380. 10.1371/journal.pntd.0004380

22. Torabi Z, Niksirat A, Mazloomzadeh S, Ahmadiafshar A: Consistency of direct microscopic examination and ELISA in detection of Giardia in stool specimen among children. Asian Pac J Trop Dis. 2014, 4:725-727. 10.1016/S2222-1808(14)60715-5

23. Ghieth MA, Kotb MA, Abu-Sarea EY, El-Badry AA: Molecular detection of giardiasis among children at Cairo university pediatrics hospitals. J Parasit Dis. 2016, 40:1470-1474. 10.1007/s12639-015-0714-9

24. Goni P, Martin B, Villacampa M, García A, Seral C, Castillo FJ, Clavel A: Evaluation of an immunochromatographic dip strip test for simultaneous detection of Cryptosporidium spp, Giardia duodenalis, and Entamoeba histolytica antigens in human faecal samples. Eur J Clin Microbiol Infect Dis. 2012, 31:2077-2082. 10.1007/s10096-012-1544-7

25. Rosoff JD, Sanders CA, Sonnad SS, et al.: Stool diagnosis of giardiasis using a commercially available enzyme immunoassay to detect Giardia-specific antigen 65 (GSA 65). J Clin Microbiol. 1989, 27:1997-2002. 10.1128/JCM.27.9.1997-2002.1989

26. Schuurman T, Lankamp P, Van Belkum A, Kooistra-Smid M, Van Zwet A: Comparison of microscopy, realtime PCR and a rapid immunoassay for the detection of in human stool specimens. Clin Microbiol Infect. 2007, 13:1186-1191. 10.1111/j.1469-0691.2007.01836.x

27. Jelinek T, Neifer S: Detection of Giardia lamblia stool samples: a comparison of two enzyme-linked immunosorbent assays. F1000Res. 2013, 39:2-7. 10.12688/f1000research.2-39.v1

28. Bouyou-Akotet MK, Owono-Medang M, Moussavou-Boussougou MN, Mamfoumbi MM, Mintsa-Nguema R, Mawili-Mboumba DP, Kombila M: Low sensitivity of the immunocardSTAT ${ }^{\circledR}$ Crypto/Giardia rapid assay test for the detection of Giardia and Cryptosporidium in fecal samples from children living in Libreville, Central Africa. J Parasit Dis. 2016, 40:1179-1183. 10.1007/s12639-015-0645-5

29. Garcia LS, Shimizu RY, Novak S, Carroll M, Chan F: Commercial assay for detection of Giardia lamblia and Cryptosporidium parvum antigens in human fecal specimens by rapid solid-phase qualitative immunochromatography. J Clin Microbiol. 2003, 41:209-212. 10.1128/JCM.41.1.209-212.2003

30. Nantavisai K, Mungthin M, Tan-ariya P, Rangsin R, Naaglor T, Leelayoova S: Evaluation of the sensitivities of DNA extraction and PCR methods for detection of Giardia duodenalis in stool specimens. J Clin Microbiol. 2007, 45:581-583. 10.1128/JCM.01823-06 